\title{
O TECIDO COLORIDO NA DANÇA-TEATRO DE PINA E BARBA: uma dramaturgia plural de subjetivação
}

\section{The colorful tissure in Pina Bausch and Eugenio Barba dance-theater: a plural subjectivity dramaturgy}

\author{
Bruno Leal Piva \\ Universidade Nova de Lisboa
}

Resumo: $O$ presente artigo tem o intuito de relacionar a composição dramatúrgica de Pina Bausch e Eugênio Barba em sua dança-teatro, a partir do envolvimento dos atoresdançarinos na criação cênica, levando em consideração suas experiências pessoais e suas participações na construção de uma narrativa plural, envolvidas por suas subjetividades ou subpartituras, num processo contínuo de subjetivação.

Palavras-chave: Dramaturgia; Pina Bausch; Eugênio Barba.

Abstract: This article aims to relate the dramaturgical composition of Pina Bausch and Eugenio Barba in their dance-theater, from the involvement of actors-dancers in the scenic creation, taking in account their personal experiences and their participation in the construction of a plural narrative, involved by their subjectivities or subpartituras, in a continuous subjectivation process.

Keywords: theatrical sign; cultural industry; spectator's pedagogy. 
Apresentação: Por que DançaTeatro?

Esta pesquisa busca verificar um entendimento sobre a construção da dramaturgia na dança-teatro de Pina Bausch, a partir de elementos exteriores e interiores da composição cênica que acionam a subjetividade do ator-dançarino, associada ao conceito de dramaturgia proposta por Eugênio Barba e sua subpartitura. Rudolf von Laban, segundo Karen Bradley (apud Juliana Silveira, 2009, p. 10), teria se apropriado pela primeira vez da expressão "dançateatro", que designaria um novo gênero, uma nova forma de arte, em que 0 movimento seria 0 foco principal de estudo, originado com ou sem música, envolvido ou não por figurino. O termo "ator-dançarino" é adotado ao longo deste trabalho para referir-se ao trabalho dos artistas dos dois diretores-encenadores, também sugerido e amplamente utilizado por Eugênio Barba (2012a, p. 14): "A antropologia teatral (...) não tem a humildade de uma ciência, e sim a ambição de identificar os conhecimentos úteis à ação do atordançarino". Ainda, sobre sua
Antropologia Teatral, afirma que se refere ao "estudo do comportamento cênico pré-expressivo que se encontra na base dos diferentes gêneros, estilos e papeis e das tradições pessoais e coletivas. Por isso, lendo a palavra 'ator', se deverá entender 'ator e bailarino'" (BARBA, 2012b, p. 22); e, ao apontar seu teatro, diz que este deve ser entendido também como dança: "ao ler 'teatro', se deverá entender 'teatro e dança"' (BARBA, 2012b, p. 22).

Nesse sentido, faz-se necessário realizar uma abordagem sobre o surgimento da dançamoderna, bem como sobre os termos a ela imbricados posteriormente, como "pós-moderno" e "pósdramático", que também dizem respeito a uma contextualização do panorama teatral.

A dança-moderna emerge de um período de potencial crescimento da indústria e de mecanização da vida cotidiana, e tenta interceptar, com outras formas das áreas artísticas, a exaltação da estética visual e do virtuosismo do ser, como por exemplo, a que se verificava na dança clássica. Tentava-se, assim, valorizar o espírito criativo do 
indivíduo, em conjunto com suas experiências e participação no mundo. Nessa relação ainda tímida entre o "eu e o mundo", a expressão corporal poderia ser eficaz através dessa mesma tensão gerada na vida e na arte, na concepção de que, segundo Matteo Bonfitto (2013, p. 09), “não há verdade na expressão, se a uma modalidade expressiva exterior não corresponder um respectivo impulso interior". Essa visão seria depois aproveitada por Isadora Duncan e Martha Graham, por exemplo, e desenvolvida por Laban. Este foi orientado por um aluno de segunda geração de Delsarte e procurou resgatar através da dança um estudo distinto e autônomo dos nomes já consagrados, e "considera o movimento como sendo o principal meio de expressão humana, que abrange o tangível e o intangível das necessidades do homem, função esta não concretizável pela palavra (...)" (BONFITTO, 2013, p. 50).

Esse furor por uma nova investigação sobre as possibilidades do corpo atraiu a atenção de Kurt Joss, um estudante de música que encontrou em Laban um estímulo para entrar no universo da dançateatro, e logo se destacou aos olhos de seu mestre. De acordo com Royd Climenhaga (apud SILVEIRA, 2009, p. 10), "o termo dança-teatro foi provavelmente usado pela primeira vez por Laban, mas foi Kurt Joss o primeiro a usá-lo de uma maneira formal e consistente." Joss era diretor da Folkwang Hochschule, quando, em 1955, Philippine Bausch (Pina Bausch) ingressa nessa escola para estudar dança e torna-se 0 maior expoente da dança-teatro: "Dança-Teatro é sinônimo de Pina Bausch", conforme cita Fabio Cypriano (2005, p. 24).

Já para Barba, dança e teatro não podem ser considerados duas formas artísticas distintas, pois uma contém e está contida na outra, e se colocadas em polos diferentes, não produzem a realização do ato cênico em toda sua essência. A expressão "dança-teatro" ou "teatro-dança", assim, encontraria suas raízes no próprio fazer direcionado ao acontecimento artístico, para além da terminologia supostamente criada pelo olhar ocidental contemporâneo. Barba (2012a, p. 19) diz que: 
A rígida distinção entre teatro e dança, que é típica da nossa cultura, revela uma profunda ferida, um vazio de tradição que está sempre correndo o risco de atrair o ator para o mutismo do corpo e o dançarino para o virtuosismo. Essa distinção soaria absurda para um artista oriental, assim como soaria absurda para artistas europeus de outras épocas (...).

\section{Pós-Moderno ou Pós-Dramático?}

Devido às divergências sobre o que constituiria 0 período pósmodernista, bem como a oferta de palavras-chave genéricas - como "ambiguidades", "não-textualidade", "pluralismo", "diversidade de códigos", "subversão", etc., como cita Hans-Thies Lehmann (2007, p. 30) -, em que alguns consideram a pósmodernidade apenas como extensão do modernismo, outros como uma ressignificação das propostas anteriores advindas dos modernistas, e considerando as discussões acerca do papel da dramaturgia para os diretores-encenadores Pina Bausch e Eugênio Barba, opta-se por designar aqui o momento de seus trabalhos como pós-dramático. Lehmann (2007, p. 24) observa que "o conceito pós-dramático, em oposição à categoria epocal 'pósmoderna', significa uma problemática teatral concreta". Silvia Fernandes, colaboradora e organizadora de $O$ Pós-Dramático: um conceito operativo? (2013), aponta que, relativo às categorizações do pósmoderno, Hans-Thies Lehmann "as rejeita, por considerá-las meramente periódicas, enquanto 0 pósdramático teria a vantagem de se referir a um problema concreto de estética teatral" (FERNANDES, 2013, p. 24). Ainda, Lehmann (2007, p. 28) inclui Eugênio Barba e Pina Bausch na categoria dos artistas do cenário pós-dramático, e conforme Ingrid Koudela, também colaboradora de $O$ Pós-Dramático..., na visão de Lehmann é preciso centrar-se no 'como', para compreender o papel da ação política "no teatro experimental, tantas vezes apelidado de pósmoderno, (...) vanguarda, teatro pop, teatro, performance (...), podem ser sintetizadas através do termo teatro pós-dramático" (KOUDELA, 2013, p. 37) e reforça a ideia de tratar os dois diretores-encenadores neste trabalho como artistas pós-dramáticos. Nas palavras de Lehmann (2007, p. 34), o teatro pós-dramático 
Supõe a presença, a readmissão e a continuidade das velhas estéticas, incluindo aquelas que já tinham dispensado a ideia dramática no plano do texto ou do teatro. A arte simplesmente não pode se desenvolver sem estabelecer relações com formas anteriores.

Poderia ser válido dizer, então, que a corrente da terminologia pósmoderna estaria mais vinculada a um divisor de épocas, situando-se em um contexto de investigação a partir de determinado momento histórico, enquanto que a de pós-dramática revelaria um campo mais amplo de estudo sobre as influências, estéticas, procedimentos e técnicas referentes à elaboração das diversas práticas artísticas. A dança-teatro, assim, estaria inserida, como indicado anteriormente, ao conceito de pós-dramático. Seria ela uma reflexão acerca do próprio fazer, uma atitude política, de questionamento e revelação do artista, de indagações e transformações procedimentais, de rompimentos estéticos e discursivos sobre a composição de suas obras, de narrar suas histórias, de expor seus "dramas": desfazer-se do antes, e durante esse pós, aproveitar os pós das cinzas como ferramentas para suas dramaturgias.

\section{Dramaturgia BBP - Brecht, Barba e Pina}

A dramaturgia, apesar de suas inúmeras definições

e aceitações/recusas no parâmetro artístico contemporâneo, parece interferir de maneira tangível as produções de Barba e Pina. A dramaturgia, aqui, deve ser entendida como a construção de ações elaboradas por atoresdançarinos que constituem uma trama, bem como todos os outros elementos pertencentes ao acontecimento cênico, como luz, som, figurino, objetos, etc., e o próprio texto, ou seja, trata-se de uma dramaturgia plural. A dançateatro pós-dramática de Pina e Barba prioriza uma dramaturgia pautada no ato criativo do ator-dançarino, que por sua vez participa da valorização de todos os recursos cênicos, como um conjunto orquestrado. Essa dramaturgia plural não visa estabelecer um entendimento único e universal para todos os espectadores 
sobre uma peça, mas prevalece nela a preocupação em como os fios condutores das dramaturgias em sua pluralidade podem afetar o olhar de todos os envolvidos, ou seja, todos os integrantes do processo, entendendo-se como processo o acontecimento cênico realizado por atores-dançarinos, autores, diretores e espectadores. Barba (2014, p. 281) defende que "a premissa de dramaturgia era pensar no plural mais de um sentido, mais de uma história, mais de um tipo de relação, uma multiplicidade e uma ramificação de elementos e linhas de desenvolvimento (...)". O destaque dado ao texto escrito ou falado de outros tempos, deste modo, fragmenta-se nas obras dos dois diretores-encenadores, emergindo junto a ele novas dramaturgias. Barba (2012a, p. 66) refere-se à dramaturgia para além do texto:

A palavra texto, antes de significar um texto falado ou escrito, impresso ou manuscrito, significava 'tessitura'. Nesse sentido, não há espetáculo sem 'texto'. O que está relacionado ao 'texto' (à tessitura) do espetáculo pode ser definido como 'dramaturgia', ou seja, dramaergon, o trabalho das ações no espetáculo. Já o modo como as ações trabalham constitui a trama.

Tal dramaturgia aplicada pelos dois pode associar-se à visão praticada por Bertolt Brecht, cujo pensamento girava em torno de um teatro aplicado a indagações sociopolíticas de sua época, rompendo com a ilusão do teatro como imitação da realidade. Para Brecht, o fazer artístico serviria como lugar de denúncia e de transformação da realidade massacrante imposta pelo crescente ritmo industrial das grandes cidades alimentadas pelo capitalismo. Segundo o autor (2005), o teatro deveria rechaçar a ideia mimética da realidade que se centrasse no comércio burguês e alavancar o espaço teatral como lugar de diversão dentro de uma estética da era científica, cujo objetivo é incitar a uma crítica, da obra à vida que se vive. Bonfitto (2013, p. 64) afirma que para Brecht, o "teatro deve associar em sua prática diversão e instrução. Por instrução, aqui, deve-se entender a estimulação de um exercício crítico, que pode levar o público a reconhecer o homem e a realidade 


\section{(...) como passíveis de} transformação", que estaria numa relação dialética com o espectador. Desta forma, conforme apontado por Bonfitto (2013, p. 64), para Brecht, a arte tem como princípio um caráter que assim deve ser entendido:

\begin{abstract}
(...) transformar o homem, mas isso só é possível, segundo ele, quando $o$ homem passa a reconhecer a si e a realidade que - envolve como passíveis de transformação, quando o homem passa a ver-se em uma existência historicizada. Compreender a natureza e a sociedade para poder dominá-las, haver controle sobre elas: esse é um dos seus principais objetivos. Mas para isso é preciso que se lide com a realidade na sua complexidade, não amenizando as tensões, mas reconhecendo suas contradições.
\end{abstract}

Brecht parece, então, ser uma figura influente no trabalho de sua conterrânea, Pina, e do italiano, Barba. O "gesto social" ou gestus ${ }^{1}$ é detalhadamente amplificado pelo olhar dos diretores-encenadores, a partir das propostas levantadas por seu atores-dançarinos, no surgimento de seus impulsos, na pulsação de experiências transfiguradas em suas ações e movimentos rítmicos, cuja tensão

\footnotetext{
${ }^{1}$ Cf. Bonfitto (2013, p. 64-65).
}

imbrica-se nas relações estabelecidas entre suas vivências cotidianas desenfreadas da contemporaneidade caótica e suas criações estéticas remetidas a construções extracotidianas do fazer artístico. Essas relações buscam como proposta uma criticização, através da arte, do ser-indivíduo inserido no mundo, nas suas particularizações engaioladas pela estrutura social que tolhe sua condição humana essencial, embora, ao mesmo tempo, necessite dessa sociedade em sua formação como ser indivíduo e social.

Barba (2014, p. 37), grande admirador de Brecht, declara que durante seu exame de admissão na escola teatral de Varsóvia, em 1961, ao ser interrogado sobre qual dramaturgia gostaria de tratar em seus estudos, entre outros nomes citados, assevera "e, naturalmente, Brecht". Em 1980, Barba cumpre sua promessa e monta As Cinzas de Brecht, com influências e personagens das obras Mãe Coragem e seus Filhos (1939) e A Resistível Ascensão de Arturo Ui (1941), ambas do escritor alemão (BARBA, 2014, p. 139). Além disso, 
relata no subcapítulo "A dança ignorada de Brecht" (2012, p. 106111) o cotidiano dos ensaios da peça O Círculo de Giz Caucasiano (1953), e utiliza o termo "préexpressividade", para associar os trabalhos dos dois, bem como faz analogia de sua subpartitura, que será analisada adiante, ao que para Brecht seria, nas palavras de Barba (2014, p. 65) "o diálogo contínuo com o qual 0 ator deveria se interrogar sobre a verdade histórica da qual sua personagem é, sem saber, a expressão subjetiva do autor". A relação do trabalho de Pina com o de seu compatriota orienta pesquisa de diversos estudiosos do teatro, como, por exemplo, Ingrid Koudela em seu livro Brecht na Pós-Modernidade (2001), e em Juliana Silveira (2015). A relação entre o trabalho de Brecht e Pina, porém, é aqui apresentada mais estritamente pelo livro de Fabio Cypriano (2005).

Enquanto o idealizador do Odin Teatret (Oslo, 1964) defende pessoalmente a influência do trabalho do fundador do Berliner Ensemble (Berlim, 1949), a diretora do Tanztheater Wuppertal no período de 1973 a 2009 (ano de sua morte) é retratada na investigação de Cypriano (2005, p. 30) como uma encenadora que dialoga com a proposta de distanciamento de Brecht, como, por exemplo, o momento em que as luzes são acesas para o espectador, a fim de quebrar com o ilusionismo de um teatro falsamente aproximado da realidade, de modo que este pudesse observar o espaço teatral como lugar de crítica e denúncia da realidade vivida pela humanidade do cotidiano individualista, fazendo-o perceber-se como integrante de um sistema em que a produção exacerbada do consumo, da indústria, da urbanidade, da sexualidade, dos desejos, dúvidas e inseguranças, frustrações e esperanças, e na falta de amparo diagnosticada nas entranhas do "cada um por si", fizessem-se presentes nos "vai e vens" da desiludida solidão presenciada na contemporaneidade.

\section{A Dramaturgia Plural na Dança- Teatro de Barba e Pina (BP) ${ }^{2}$}




\section{Tanto Pina como Barba} revelam em suas dramaturgias, assim como Brecht, essa preocupação em fazer do artista um canal e instrumento que exteriorizem suas indagações pessoais, a partir das experienciações relativas aos modos de pensar e atuar no mundo. Expõem suas dramaturgias não apenas desenhadas por ações corporais e vocais compostas pelos atores-dançarinos e coordenadas pelos diretores-encenadores, mas também pela relação travada entre aqueles $e$ todos os elementos cênicos, como as luzes, os sons, os espaços etc., que constituem o tecido narrativo, um tecido plural, formado por vários tons e cores. Nesse sentido, as ações são composições surgidas, como elucida Barba (2012a, p. 66),

de todas as interações entre personagens entre si ou entre eles e as luzes, os sons, o espaço. Tudo o que age diretamente sobre a atenção do espectador, sobre sua compreensão, sua emotividade e sua cinestesia também é ação (...). Importante é observar que as ações só começam a trabalhar quando se entrelaçam: quando se tornam tecido, textura = 'texto'.
Pina parece pensar essa dramaturgia de modo semelhante, quando utiliza em seu "método", conforme explicita Lehmann, (2007, p. 340), uma configuração dramatúrgica baseada no entrelaçamento das ações exploradas pelo corpo, por meio do uso de imagens cênicas, molduradas por materiais muitas vezes extraídos da própria natureza, como água, terra, flores, fuligem e folhagem, aproximando arte à natureza, corpos a realidades: "Assim como os objetos, os gestos corporais são perceptíveis como realidades antes de toda significação, de modo que não conseguimos perceber efetivamente a realidade exterior no percurso da visão, orientada cada vez mais para o abstrato" (LEHMANN, 2007, p. 340).

Barba acredita que a força expressada pelas experiências pessoais dos atores-dançarinos, em suas composições artísticas, possui regência fundamental na construção da dramaturgia de um espetáculo. Para ele, a dramaturgia é a execução proposta pelos indivíduos que a constituem, através de suas atuações no meio em que vivem e 
dos elementos que dialogam no momento da criação cênica. No Odin Teatret, "a dramaturgia do ator não era um modo de representar, mas uma técnica para realizar ações reais na ficção da cena" (BARBA, 2014, p. $60)$.

diretor italiano (2014) define o trabalho do ator-dançarino como dramaturgia do ator, o qual estabelece uma lógica que não corresponde às intenções do diretor nem do autor, mas sim da lógica extraída do ator-dançarino a partir de suas próprias experiências e existência, na relação com diretor e seus companheiros de cena. Dessa maneira, ele contribui com uma composição que possui um valor em si mesma, em sua autonomia como indivíduo e artista. A partir de então, o diretor-encenador poderia desenvolver os três níveis de organização dessa dramaturgia: a primeira é a orgânica, que trata sobre o nível essencial e se relaciona com a maneira de compor e entreter os ritmos e ações físicas e vocais dos atores-dançarinos, para estimular sensorialmente 0 olhar do espectador, através de seus impulsos associativos com elementos externos e interiores. A "dramaturgia orgânica é constituída pela orquestração de todas as ações dos atores consideradas sinais dinâmicos e cinestésicos. Seu objetivo é a criação de um teatro que dança" (BARBA, 2014, p. 59). A segunda, a dramaturgia narrativa, é da trama das sucessões que orientam os espectadores acerca do sentido ou dos múltiplos sentidos dos espetáculos, por meio do tecer dos fios que o constituem; por último, a dramaturgia evocativa, refere-se à ressonância ou os níveis de revelação causada no íntimo do espectador, de onde surge a sombra, que é "projetada pelo organismo vivo do espetáculo, aquela que provocava uma mudança de estado no espectador" (BARBA, 2014, p. 258).

$A$ dramaturgia de Pina aproxima-se dos princípios propostos por Barba, no que diz respeito, não só à valorização da pluralidade das dramaturgias, ou seja, aquela que consiste na união dos três níveis de organização sugeridos pelo fundador do Odin Teatret, mas também se percebe no trabalho de ambos a relevância do trato dado à composição, primeiramente, a partir 
das sugestões de ações dos atoresdançarinos, que advém de lugares de todo o mundo. Nessa composição inter ou transcultural, não há valorização de uma cultura sobre a outra, mas a sua intersecção conduz ao enriquecimento de uma construção cênica pautada em mesclas de intelecções de mundo.

Barba é um viajante por excelência: o peregrino tem em seu passaporte o registro de visitas em vários lugares do mundo, incluindo em sua trajetória pessoal e profissional técnicas advindas de diversos países orientais. As viagens e as influências que Barba utiliza como propulsores de sua dançateatro podem ser verificadas em todas suas obras. O relato de suas experiências e as técnicas observadas - como da Ópera de Pequim, Teatro de Bali, Odissi e Kathakali - por ele estão em constante uso em sua Antropologia Teatral. Tanto na escola ISTA como na companhia teatral de Odin, os grupos são formados por atoresdançarinos de todos os lugares do planeta.

Essa transculturalidade também esteve presente durante a direção da diretora do Wuppertal, que ainda estudante sempre esteve em contato com outras culturas para alcançar novos olhares sobre a humanidade e utilizá-los, assim, em seus trabalhos profissionais, mas indissociavelmente também como investigação pessoal no modo de como interpretar e atuar no mundo. Além disso, conforme Cypriano (2005, p. 36), a partir de 1980, ela começou a se inspirar em culturas locais para criar seus espetáculos, como em Bandoneon (1980), que leva tangos argentinos e a desconstrução de seus movimentos pelos bailarinos. Para o crítico alemão Jochen Schmidt (apud CYPRIANO, 2005, p. 35), as viagens da Cia. liderada na época por Pina eram essenciais, em que "O Tanztheater Wuppertal

e especialmente sua diretora (...) usam o tempo para, de forma intensiva, conhecer as pessoas e seu ambiente. Não raramente, ela busca unir o útil ao agradável".

Cypriano (2005, p. 36) chama essas influências transculturais de "coreo-geografias", utilizadas no processo e na montagem dos espetáculos da alemã, de acordo 
com as peculiaridades observadas em suas visitações estrangeiras. Desse modo, esse pensamento se aproxima à visão de "coreo-política" de Lepecki (2011), em que nela há um entrelaçamento entre corpo, movimento e lugar; o movimento dos cidadãos (polis) em seu espaço (arquitetura - urbano), que pode se transformar pela não ação das tendências habituais, resultando numa ação política - deixar a dança dançar e 0 inesperado surgir, desequilibrar e desestabilizar.

O "método" utilizado por ambos, como visto anteriormente, é pautado no levantamento de experiências anteriores de seus atores-dançarinos, que inicialmente alavancam o processo das criações cênicas e passam a experimentar ações voltadas às construções de partituras que, adicionadas à cumplicidade estabelecida entre estes e seu público, torna-se primordial dentro dum resgate espiritual, da conexão com o mundo, produzida na zona intermediária que é a dança-teatro. Porém, quanto mais fragmentada e ambígua for a dramaturgia, maior será a ativação sensorial do artista no ato e maior a motivação para sensibilização do espectador. Essa perspectiva tornase mais interessante e eficiente, quando se lança um olhar pedagógico sobre os modos como os atores-dançarinos podem criar suas dramaturgias. Quando os artistas, tanto ator-dançarino e diretor, caminham em processo colaborativo, em que o segundo provoca soluções ou confusões para o desenvolvimento da dramaturgia cênica, intermediando e instigando o jogo e as improvisações, mirando e alinhando de fora o quadro que será construído, participando de dentro das pulsações eminentes e iminentes dos atores-dançarinos, emerge daí um trabalho forte, significativo e transformador.

\section{Subjetividade e Subpartitura na Dramaturgia Plural de BP}

Enquanto Barba inicia seu processo de trabalho, inclinando-se sobre as particularizações levantadas pelas ações improvisadas por seus atores-dançarinos, estimulando-os a conectarem-se com elementos exteriores e interiores do espaço, Pina parecia não agir 
diferente. Ambos procuram trabalhar a potência de improvisação de seus atores-dançarinos, a partir da indicação de algum tema, que depois resultaria numa série de ações levadas a alternância de ritmos, tempos, formas etc., fixando-as em repetições que passavam a constituir as partituras. Explicita Barba:

O momento essencial não era a improvisação em si, mas a fase imediatamente sucessiva, quando a improvisação era memorizada e fixada pelos atores, tornando-se uma partitura precisa. Naquele estágio de nossa experiência, a improvisação constituía a via mais eficaz para construir um desenho de movimentos que tivesse raízes na história pessoal e profissional do ator (...) Essa primeira fase de elaboração consiste num trabalho pessoal de composição semelhante ao trabalho de uma autocoreografia. (2012b, p. 100)

Depois da montagem de Blaubert (O Barba Azul, de 1978), rechaçada pelo público, Pina começou a investir naquilo que viria a ser o seu método de perguntas que fossem respondidas pelo atordançarino, de acordo com seu contato mais íntimo na observação com o espaço exterior, para retirar dele todo substrato humano essencial que remetesse a ações "improvisadas"

desenvolvidas, destinadas à constituição de partituras altamente significativas ${ }^{3}$. Cypriano (2005, p. 20) afirma:

As respostas levadas ao palco tratam essencialmente de questões existenciais: amor e ódio, medo e compreensão, solidão e companheirismo, repressão e alegria. Esses motivos aparecem no palco sob formas múltiplas: na dança, no choro, no riso, na voz e no gestual do elenco. Todo modo de comunicação é válido para a dança-teatro da coreógrafa. E o palco é sempre um ambiente que propicia contrastes para essa abordagem; transforma-se numa realidade irreal, por meio do uso de elementos naturais - coberto de água, grama ou terra, por exemplo. Pela reunião de todos esses elementos, pode-se afirmar que ela expandiu as fronteiras da dança.

Geralmente, a diretora do Wuppertal levava uma lista de 100 e 200 perguntas, sendo uma média de cinco questões por ensaio ${ }^{4}$. As improvisações e as expressões apareciam como respostas, através de palavras, movimentos e outras combinações dos atores-dançarinos, do modo como melhor thes conviesse, e a encenadora cada vez

3 Wilne Souza Fantini e Iraquitan Oliveira Caminha (2016, p. 192-193) citam sobre esse caminho de Pina.

${ }^{4}$ Cf. Ciane Fernandes (2007). 
menos, com o passar do tempo, interferia nas propostas deles. As ideias e movimentos surgidos das improvisações eram anotados ou gravados em vídeo, e dentre os mais proveitosos selecionava-os para serem repetidos, em direção de uma busca pela forma.

Assim, Pina criava conjuntamente com seus atoresdançarinos. Em início de processo, a coreógrafa levava sua companhia para lugares onde o corpo pudesse dialogar com o espaço, cujo tema estivesse inserido nas preocupações mais latentes do local a ser desenhado pelo grupo. No decorrer do processo, a coreógrafa costumava regressar ao Wuppertal com um material bem amplo, consolidado pelas experiências dos artistas e dela própria. Assim, ela podia explorar os sentimentos humanos vivenciados e escondidos, cujo objetivo era o de potencializá-los como base de criação artística. Ela comprova com suas palavras, em obra de Cypriano, que

A dança deve ter outra razão além de simples técnica e perícia. A técnica é importante, mas é só um fundamento. Certas coisas se podem dizer com palavras, e outras, com movimentos. Há instantes, porém, em que perdemos totalmente a fala, em que ficamos totalmente pasmos e perplexos, sem saber para onde ir. É aí que tem início a dança, e por razões inteiramente outras, não por razões de vaidade. Não para mostrar que os dançarinos são capazes de algo de que um espectador não é. É preciso encontrar uma linguagem com palavras, com imagens, movimentos, estados de ânimo, que faça pressentir algo que está sempre presente. Esse é um saber bastante preciso. Nossos sentimentos, todos eles, são muito precisos, mas é um processo muito, muito difícil torná-los visíveis. (...) Não se trata de arte, tampouco de mero talento. Tratase da vida e, portanto, de encontrar uma linguagem para a vida. E, como sempre, trata-se do que ainda não é arte, mas daquilo que talvez possa se tornar arte. (apud CYPRIANO, 2005, p. 28-29)

As partituras, fixadas e memorizadas após experimentações e tentativas, podem ser vistas como resultado de ativações das subjetividades - ou subpartituras anteriores e decorrentes de experienciações vivenciadas do atordançarino durante 0 processo de criação artística, absorvidas em campo estrangeiro - entende-se por estrangeiro aquele ou aquilo fora do lugar habitual ou originário, em 
espaço geográfico, humano, político ou social, em que as experienciações sensoriais unem-se e se estabelecem por meio de um conjunto de relações heterogêneas ou híbridas. Por meio das dramaturgias criadas e inscritas na expressão corporal e sua organicidade - aliadas aos demais elementos cênicos - cria-se um diálogo com os envolvidos. Percebese, desde aqui, uma articulação inevitável entre subjetividade e subpartitura.

De toda a trajetória percorrida por Pina, torna-se favorável identificar a subjetividade na sua execução em Café Müller (1978), em que a diretora alemã leva aos palcos uma recordação íntima de sua infância. Criada em ambientes livres, enquanto seu pai ocupava-se de um restaurante, muitas vezes ela era obrigada a ver-se entre os muitos andares de pés transeuntes no estabelecimento paterno. Tentava identificar em seus passos características que remetessem às suas personalidades. Muitos anos depois, surge no espetáculo de 1978 as experienciações tomadas no restaurante que pertencia ao seu pai.
A autora deixa-se tomar pela subjetividade que a repele à criação de sua dança-teatro, mas não a reconhece como autora única de seu vislumbramento: parte do princípio de que todos os atuantes, tanto as pessoas que passaram no comércio do pai, como os artistas-dançarinos de sua dança-teatro, compõem sua obra repleta sobre 0 seu reconhecimento e questionamentos humanos e sua relação com 0 mundo. Segundo André Lepecki (2006, p. 08), o conceito de subjetividade da "modernidade" leva muitas vezes a uma falsa ideia de "sujeito fixo" e, ao contrário, esse conceito deve ser dinâmico e expressar ações ligadas à política, aos afetos, à dança etc., ou seja, deve ser entendida como processo de subjetivação, na possibilidade de inventar e reinventar a vida pela arte, sob a perspectiva de um "modo intensivo, e não de um sujeito pessoal" imutável. Esse pensamento de Lepecki contribui para tentar validar a aproximação entre as dramaturgias propostas pelos diretores-encenadores - $\quad$ sem esquecer a de Brecht -, à medida que sua visão contemporânea sobre 
a dança estabelece laços estreitos com o questionamento do sujeitoindivíduo na arte, criador e transformador de realidades em ato político e por meio do fazer artístico. Trata-se mais que de uma subjetivação individual, mas de uma concepção de relações sociais e ética coletiva, e apesar da representação universalista da contemporaneidade acerca da subjetividade caminhar à falência, há, em contraponto, o aumento de reivindicações de singularidade subjetiva.

Entre tantas suposições sobre a eficácia da originalidade e a pessoalidade de atorescompositores-dançarinos na composição ou dramaturgia das obras, Barba expõe de modo prático a teoria de sua subpartitura, equivalendo-se da subjetividade como o preenchimento das ações transformadas em partituras. Esse preenchimento é bem conceituado e discutido pelo diretor-pedagogo italiano, cujo teor pode ser identificado no procedimento criativo de Pina. Para Barba (2012a, p. 122123), a subpartitura do atordançarino é o "invisível" que dá vida ao que 0 espectador vê, um processo profundamente pessoal, difícil de se compreender ou explicar e não consiste necessariamente nas intenções ou nos pensamentos não expressos de um personagem. $O$ visível é trabalhado pelos exercícios praticados durante um processo, como o uso das repetições das formas vazias que depois de dominadas precisam ser preenchidas por improvisações, ou seja, variar a execução com ritmos, imagens ou com os encadeamentos das associações mentais. Assim surge a subpartitura, pela partitura de um exercício, o valor do visível e do invisível, partitura e subpartitura, num diálogo contínuo que $\mathrm{o}$ ator sente como interioridade e é aquilo que o espectador experimenta como interpretação.

Como foi abordado acima, a partitura era elaborada, no trabalho dos atores-dançarinos do Wuppertal e do Odin Teatret, a partir de uma série de ações improvisadas, repetidas muitas vezes em diferentes ritmos, tempos, formas, até sua fixação. Essa partitura era a construção artificial das ações, a forma, que após longo período de 
dilatação era revestida por um forro escondido que motivava, com a qualidade de energia, essas ações: a subpartitura, que também pode ser encontrada com diferentes nomes subtexto, subjetividade, por exemplo. Segundo Barba,

A subpartitura é um elemento técnico que pertence à particular lógica criativa de cada ator. (...) um estudo sobre o ator e para o ator (...) é um apoio interno, um pilar escondido que o ator esboça para si e que não tenta representar. (...) Sem a subpartitura, aquilo que 0 ator representa não é mais a criação de uma corrente subjetiva de reações, uma linha orgânica guiada por uma coerência interna, mas gesticulação, movimentos e deslocamentos casuais. (2014, pp. 64-65)

Ainda, segundo ele (apud BONFITTO, 2013, p. 80) "qualquer que seja a estética da encenação, deve existir uma relação entre partitura e a 'subpartitura', os pontos de apoio, a mobilização interna do ator". Bonfitto (2013, p. 82) afirma também que "por subpartitura devese entender todos os procedimentos que envolvem a interioridade do ator a fim de preencher, dar vida e justificar a partitura".
Constata-se, nos trabalhos e propostas de Barba e Pina, que a dramaturgia constitui-se de diversos elementos componentes de um espetáculo, isto é, desde as ações improvisadas, ritmos alternados, repetições, partituras e subpartituras - estas últimas como o revestimento de carga subjetiva e significativa para o ator e, consequentemente, para o espectador -, até as luzes, a disposição do espaço, os sons, os figurinos, etc., que, concatenados, resultam numa organicidade, narrativa e evocação. A dramaturgia específica do ator-dançarino significa (BARBA, 2012a, p. 124), sobretudo, a capacidade de construir 0 equivalente da complexidade que caracteriza a ação na vida e de toda forma vivente, e de estimular reações afetivas, não apenas como uma emoção arrebatadora, mas como uma complexa trama de reações que levem não só o ator-dançarino e o espectador, mas também o diretorencenador, a observarem-se como seres atuantes, críticos e protagonistas de suas histórias, construídas com o outro e seu meio. $E$ é essa a dramaturgia pósdramática dos dois diretores- 
encenadores que estampa em seu tecido uma preocupação para além da estética: aquece ou resfria, mas de qualquer modo introduz um desafio ao homem contemporâneo, através da dança-teatro, de reconhecer-se em uma atitude crítica como indivíduo de sua sociedade, a partir de elementos exteriores e interiores, norteadores de sua construção dramatúrgica: um tecido colorido que Pina e Barba tecem zelosamente não apenas a partir de suas próprias experiências, mas em conjunto com subjetividades ou subpartituras propostas por seus atores-dançarinos, reveladas em e por suas peles plurais, individuais e coletivas, políticas e artísticas.

Recebido em 27/12/2018

Aceito em 31/01/2019

\section{Referências Bibliográficas}

BARBA, Eugênio \& SAVARESE, Nicola. A Arte Secreta do Ator: Um Dicionário de Antropologia Teatral. São Paulo: É Realizações Editora, 2012a.

BARBA, Eugênio. A Canoa de Papel: Tratado de Antropologia Teatral. Brasília: Dulcina Editora, 2012b.

BARBA, Eugênio. Queimar a Casa.

São Paulo: Perspectiva, 2014.
BAUSCH, Pina. (1978). Cafe Müller. Disponível

$<$ www.youtube.com/watch? $v=W Z d 2 S$ kydIXA>. Acesso em: 27/10/2017.

BONFITTO, Matteo. o Ator Compositor - as ações físicas como eixo: de Stanislávski a Barba. São Paulo: Perspectiva, 2013.

BRECHT, Bertolt. Estudos sobre teatro. Rio de Janeiro: Nova Fronteira, 2005.

CYPRIANO, Fabio. Pina Bausch. São Paulo: Cosac Naif, 2005.

FANTINI, Wilne Souza e CAMINHA, Iraquitan Oliveira. (2016). O Paradoxo na Dança Teatro de Pina Bausch. Moringa Artes do Espetáculo, João Pessoa, UFPB, v. 7 n. 1, jan/jun 2016, p. 187 a 203. Disponível em $<$ www.periodicos.ufpb.br/index.php/ moringa/article/view/29329/15665>. Acesso em 25/11/2017.

FERNANDES, Ciane. Pina Bausch e 0 Wuppertal dança-teatro: repetição e transformação. São Paulo: Annablume, 2007.

FERNANDES, Sílvia. Teatros PósDramáticos. In: GUINSBURG, Jacob; (Orgs.). O Pós-Dramático Um Conceito Operativo?. São Paulo: Perspectiva, 2013. p. 11-30.

GUINSBURG, Jacob; FERNANDES, Sílvia (Orgs.). O Pós-Dramático Um Conceito Operativo?. São Paulo: Perspectiva, 2013. 
KOUDELA, Ingrid. Brecht na pós-
modernidade. $\quad$ São Paulo:

Perspectiva, 2001.

KOUDELA, Ingrid. O Teatro Político e o Pós-Dramático. In: GUINSBURG, Jacob; FERNANDES, Sílvia (Orgs.). O Pós-Dramático - Um Conceito Operativo?. São Paulo: Perspectiva, 2013. p. 31-42.

LEHMANN, Hans-Thies. 0 teatro pós-dramático. São Paulo: Cosac Naify, 2007.

LEPECKI, André. (2011). Coreopolítica e coreo-polícia. Ilha Revista de Antropologia, 13 (1,2), 41-60. Disponível em $<$ http://doi.org/10.5007/21758034.2011v13n1-2p41>. Acesso em $30 / 11 / 2017$.

LEPECKI, André. Exhausting Dance: Performance and Politcs of Movement. New York and London: Routledge, 2006.

SILVEIRA, Juliana C. F. (2009). Contextualização da Dança-Teatro de Pina Bausch. Revista Cena em Movimento, Belo Horizonte, UFMG, Edição no 1, p. 1 a 21. Disponível em <http://seer.ufrgs.br/cenamov/article/ view/21603>. Acesso em 29/11/2017.

SILVEIRA, Juliana C. F. Dramaturgia na dança teatro de Pina Bausch. Belo Horizonte: Editora UFMG, 2015. 
Moringa Artes do Espetáculo, João Pessoa, UFPB, v. 10 n. 1, jan-jun/2019, p. 181 a 200

\section{morinda}

